\title{
Authors' Response to Comment on: “Development of a Revised Conceptual Framework of Physical Training for Use in Research"
}

\author{
Annie Jeffries $^{1} \cdot$ Samuele Marcora $^{2,3} \cdot$ Aaron Coutts $^{1} \cdot$ Lee Wallace $^{1} \cdot$ Alan McCall $^{1,4} \cdot$ Franco Impellizzeri $^{1}$
}

Accepted: 16 December 2021 / Published online: 3 January 2022

(c) The Author(s), under exclusive licence to Springer Nature Switzerland AG 2021

\section{Dear Editor,}

We thank the authors of the letter [1] for their interest in our proposed conceptual framework for physical training [2]. The contribution of Bertollo et al. [1] from a sport psychology perspective is greatly appreciated and we believe the authors succeeded in their attempt to integrate a different but complementary perspective on an interdisciplinary approach as advocated by the Grand Unified Theory proposed by Paul Glazier (2017) [3].

When developing and explaining the proposed framework [2], we focused on areas more directly related to physical training, and in which all the authors of this theoretical framework possess a specific expertise. As a consequence, the psychological aspects have been mentioned but not explored or more deeply addressed. Similarly, we referred to athlete-reported outcome measures from a clinimetric perspective. Accordingly, we focused on symptoms and physical signs resulting from training and thus did not address specifically the issues of traits and states. Nevertheless, as we indicated in Table 1 of our paper [2], many of the

This comment refers to the article available online at https://doi. org/10.1007/s40279-021-01551-5.

This reply refers to the comment available online at https://doi.org/ 10.1007/s40279-021-01629-0.

Annie Jeffries

Annie.Jeffries@uts.edu.au

1 Faculty of Health, Human Performance Research Centre, University of Technology Sydney, UTS Moore Park Precinct, Level 3, Corner of Moore Park Rd and Driver Avenue, Moore Park, Sydney, NSW 2021, Australia

2 Endurance Research Group, School of Sport and Exercise Sciences, University of Kent, Canterbury, UK

3 Department of Biomedical and Neuromotor Sciences (DIBINEM), University of Bologna, Bologna, Italy

4 Arsenal Performance and Research Team, Arsenal Football Club, London, UK individual factors that affect training are psychological traits and states. Furthermore, many of the acute training effects we mentioned (e.g. subjective feelings of fatigue) can also be classified as psychological states if one prefers to use psychological, rather than clinimetric, jargon.

The further explanation of the concepts of trait and states by Bertollo et al. [1] is relevant because it is crucial in the selection of the correct psychometric instruments, now commonly used by sport scientists and practitioners [4]. As such, understanding whether practitioners wish to assess traits or states should drive the selection of the appropriate instrument, as well as the validation of new instruments.

\section{Declarations}

Funding No sources of funding were used to assist in the preparation of this letter.

Conflicts of interest/Competing interests Annie Jeffries, Samuele Marcora, Aaron Coutts, Lee Wallace, Alan McCall and Franco Impellizzeri declare that they have no conflicts of interest relevant to the content of this letter.

\section{References}

1. Bertollo M, Santi G, di Fronso S. Comment on: "Development of a revised conceptual framework of physical training for use in research." Sports Med. 2021. https://doi.org/10.1007/ s40279-021-01629-0.

2. Jeffries AC, Marcora SM, Coutts AJ, Wallace L, McCall A, Impellizzeri FM. Development of a revised conceptual framework of physical training for use in research and practice. Sports Med. 2021. https://doi.org/10.1007/s40279-021-01551-5.

3. Glazier PS. Towards a grand unified theory of sports performance. Hum Mov Sci. 2017;56(Pt A):139-56.

4. Jeffries AC, Wallace L, Coutts AJ, McLaren SJ, McCall A, Impellizzeri FM. Athlete-reported outcome measures for monitoring training responses: a systematic review of risk of bias and measurement property quality according to the COSMIN guidelines. Int J Sports Physiol Perform. 2020;15(9):1203-15. 